\title{
Ventilatory equivalent for oxygen as an extubation outcome predictor: A pilot study
}

\author{
Troy Ellens ${ }^{1}$, Ramandeep Kaur MS² , Kelly Roehl MS³, Meagan Dubosky MS ${ }^{4}$, David L. Vines $\mathrm{MS}^{2}$
}

\begin{abstract}
T Ellens, R Kaur, K Roehl, M Dubosky, DL Vines. Ventilatory equivalent for oxygen as an extubation outcome predictor: A pilot study. Can J Respir Ther 2019;55:65-71. doi: 10.29390/cjrt-2019-007. (Corrigendum: Can J Respir Ther 2019;55:72. doi: 10.29390/cjrt-2019-009)

Introduction: Weaning predictors can help liberate patients in a timely manner from mechanical ventilation. Ventilatory equivalent for oxygen $\left(\mathrm{VEqO}_{2}\right)$, a surrogate for work of breathing and a measure of the efficiency of breathing, may be an important noninvasive alternative to other weaning predictors. Our study's purpose was to observe any differences in $\mathrm{VEqO}_{2}$ between extubation outcome groups.

Methods: Employing a metabolic cart, oxygen consumption $\left(\dot{V}_{2}\right)$, minute volume $(\mathrm{VE})$, tidal volume $(\mathrm{VT})$, and breathing frequency were recorded during a spontaneous breathing trial (SBT) to calculate $\mathrm{VEqO}_{2}$ and the rapid shallow breathing index (RSBI) in 34 adult participants in the intensive care unit. Five-breath means of $\mathrm{VEqO}_{2}$ and the RSBI collected throughout the SBT were examined between SBT pass and fail groups and extubation pass and fail groups using the Mann-Whitney $\mathrm{U}$ test with $p<0.05$.

Results: Data from 31 participants were analyzed between SBT outcome groups. Data from 20 participants were examined for extubation outcome after a successful SBT. Median (interquartile range) $\mathrm{VEqO}_{2}$ was not different between extubation groups. Participants who passed the SBT had a higher median $\mathrm{VEqO}_{2}$ than those who did not at the midpoint $\left(25.3 \mathrm{~L} / \mathrm{L} \mathrm{VO}_{2}\left[22-33 \mathrm{~L} / \mathrm{L} \dot{V} \mathrm{O}_{2}\right]\right.$ vs. $\left.23.7 \mathrm{~L} / \mathrm{L} \dot{\mathrm{VO}}{ }_{2}\left[18-24 \mathrm{~L} / \mathrm{L} \dot{\mathrm{V}} \mathrm{O}_{2}\right], p=0.035\right)$ and at the end $\left(25.5 \mathrm{~L} / \mathrm{L} \dot{\mathrm{V}} \mathrm{O}_{2}\left[23-34 \mathrm{~L} / \mathrm{L} \dot{V} \mathrm{O}_{2}\right]\right.$ vs. $\left.21.3 \mathrm{~L} / \mathrm{L} \dot{V} \mathrm{O}_{2}\left[20-24 \mathrm{~L} / \mathrm{L}^{2} \mathrm{O}_{2}\right], p=0.017\right)$ of the SBT.

Discussion: $\mathrm{VEqO}_{2}$ may show differences in SBT outcomes, but not differences between extubation outcomes. $\mathrm{VEqO}_{2}$ may be able to detect differences in work during an SBT, but may not be able to predict change in workload in the respiratory system after extubation. The small sample size may also have prevented any differences in extubation outcomes to be shown.

Conclusion: $\mathrm{VEqO}_{2}$ was higher in patients that passed their $\mathrm{SBT}$. $\mathrm{VEqO}_{2}$ was not useful in identifying extubation success or failure in adult mechanically ventilated patients.
\end{abstract}

Key Words: mechanical ventilation; work of breathing; rapid shallow breathing index; spontaneous breathing trial; oxygen consumption

\section{INTRODUCTION}

Prolonged mechanical ventilation comes with many health risks to a patient $[1,2]$, and a failed extubation requiring subsequent reintubation significantly increases the risk of nosocomial pneumonia that is associated with an increased mortality risk [3, 4]. For these reasons, in 2017 the American Thoracic Society and the American College of Chest Physicians developed guidelines for liberating critically ill adults from mechanical ventilation. These guidelines focused on answering questions regarding the spontaneous breathing trial (SBT), the use of sedation and liberation protocols, and cuff leak tests among other questions. Although the group purposefully chose to focus on six key clinical questions, the guidelines did not make recommendations towards the use of any weaning or extubation predictors. The guideline summary quotes that "patients at high risk for failure of extubation may include those patients with hypercapnia, chronic obstructive pulmonary disease, congestive heart failure, or other serious comorbidities" [5]. Objectively identifying patients at higher risk for reintubation and predicting extubation success or failure is difficult.

The aforementioned guidelines may not recommend any specific weaning predictors or indexes because many that have been studied show only modest predictive accuracy in weaning and also perform poorly in predicting extubation outcomes [6-8]. The McMaster review mentions 66 weaning predictors that have been studied, only a handful of which showed modest predictive accuracy for weaning. These include minute volume (VE), negative inspiratory force (or maximum inspiratory pressure $\left(\mathrm{P}_{\mathrm{I}} \mathrm{Max}\right)$ ), $\mathrm{P}_{0.1} /$ maximum inspiratory force, $\mathrm{CROP}$ (compliance, rate, oxygenation, and pressure) index, respiratory rate (RR), tidal volume (VT), and the RR/VT or rapid shallow breathing index (RSBI) [1]. Those with a higher predictive accuracy at certain thresholds for extubation outcomes are the RR, RSBI, $\mathrm{P}_{\mathrm{I}} \mathrm{Max}$, and acute physiology and chronic health evaluation (APACHE) II scores at admission [6]. And not all are observed during the time of the SBT, as may be the case with predictors like $\mathrm{P}_{\mathrm{I}} \mathrm{Max}$ or APACHE scores at admission. Moreover, many studies verifying the efficacy of the RSBI, the most commonly used predictor in conjunction with an SBT to predict extubation outcomes, have reported threshold values different from the original study and high rates of false positives and false negatives, largely due to differences in methods and patient populations [9-11]. The strongest predictors integrate more than a single physiological measure or parameter. The Integrative Weaning Index (the product of the static compliance of the

${ }^{1}$ Quality Improvement Systems, James. M. Anderson Center for Health Systems Excellence, Cincinnati Children's Hospital Medical Center, Cincinnati, $\mathrm{OH}$, USA

${ }^{2}$ Department of Cardiopulmonary Sciences, Division of Respiratory Care, Rush University, Chicago, IL, USA

${ }^{3}$ Department of Nutrition, Rush University, Chicago, IL, USA

${ }^{4}$ Department of Pulmonary and Sleep Medicine, DuPage Medical Group, Chicago, IL, USA

Correspondence: Troy Ellens, Cincinnati Children's Hospital Medical Center, 3333 Burnet Ave., Location A, 7th Floor, Suite 174, Cincinnati, OH 45229, USA.E-mail: troy.ellens@cchmc.org

Published online at https://www.cjrt.ca on 30 September 2019

This open-access article is distributed under the terms of the Creative Commons Attribution Non-Commercial License (CC BY-NC) (http:// creativecommons.org/licenses/by-nc/4.0/), which permits reuse, distribution and reproduction of the article, provided that the original work is properly cited and the reuse is restricted to noncommercial purposes. For commercial reuse, contact editor@csrt.com 
respiratory system and the ratio of arterial oxygen saturation to the $\mathrm{RSBI}$ ), the CROP index, and the RSBI are three such indexes that show more promise as weaning predictors [1, 12, 13]. Studies examining more objective extubation predictors are warranted.

The ventilatory equivalent for oxygen $\left(\mathrm{VEqO}_{2}\right)$ may be a feasible, objective tool to predict the ability to spontaneously breathe or extubation outcomes. Ruppel defined $\mathrm{VEqO}_{2}$ as "a measure of the efficiency of the ventilator pump at various workloads" [14]. Used in cardiopulmonary exercise testing, $\mathrm{VEqO}_{2}$ is the ratio of a person's minute ventilation (VE) in liters to oxygen consumption $\left(\mathrm{VO}_{2}\right)$ in milliliters/minute $\left(\mathrm{VE} / \mathrm{VO}_{2}\right)$ [14]. Oxygen consumption, or the oxygen cost of breathing (OCOB), has been studied to estimate the work of the respiratory muscles using indirect calorimetry. Changes in oxygen consumption and central venous saturation at different levels of ventilator support have been assessed to predict the ability to spontaneously breathe and the extubation outcomes, but study results have varied [15-20]. The oxygen cost of breathing is closely related to the mean pressure created by the diaphragm [21], which is why studies around spontaneous modes of mechanical ventilation, like proportional assist ventilation and pressure support ventilation have included the pressure-time product (PTP) as a measure for patient effort at varying levels of ventilator support [21-25]. $\mathrm{VEqO}_{2}$ includes oxygen consumption as a part of its measurement, but could also be used as a surrogate for the PTP or work of breathing (WOB), which has also been studied in weaning and extubation outcomes [24, 26-31]. However, measuring both the PTP and WOB requires the insertion of an esophageal balloon, or other more sophisticated and expensive methods such as artificial neural networks [26]. Differences in $\mathrm{VEqO}_{2}$ have been shown in patients with emphysema and were compared between ventilator modes in healthy patients using indirect calorimetry $[32,33]$. In addition to determining nutritional needs, ventilators that incorporate indirect calorimetry technology could be used to determine the $\mathrm{VEqO}_{2}$ in intubated patients. Measurement of $\mathrm{VEqO}_{2}$ provides a safe, noninvasive way to measure the ventilatory efficiency in patients during weaning or prior to extubation. The purpose of this study was to determine if there was a significant difference in $\mathrm{VEqO}_{2}$ between patients that failed and those that successfully completed a spontaneous breathing trial and extubation in adult mechanically ventilated patients.

\section{METHODS}

This pilot study evaluating $\mathrm{VEqO}_{2}$ between patient extubation outcome groups recorded during a spontaneous breathing trial was a prospective, observational study conducted at Rush University Medical Center, Chicago, Illinois, from 2013 to 2016. The protocol was approved with a waiver of consent by the Institutional Review Board at Rush University Medical Center.

\section{Participants}

Thirty-four participants who were $\geq 18$ years of age and met the inclusion and exclusion criteria for study were consecutively enrolled. Any participant who was intubated, on the mechanical ventilator for at least $24 \mathrm{~h}$, hemodynamically stable, with adequate oxygenation and ventilation per the institutions weaning guidelines (Figure 1) or had a physician's order for an SBT was enrolled into the study. Participants were excluded from the study if they had a tracheostomy, high oxygen requirements, neuromuscular disease, or large air leaks such as chest tubes, bronchopleural fistula, or tracheomalacia.

\section{Measurements}

To compare $\mathrm{VEqO}_{2}$ with a previously verified parameter assessed during spontaneous breathing, RSBI was also recorded and compared between groups. Data pertaining to the determination of $\mathrm{VEqO}_{2}$ and $\mathrm{RSBI}$ are $\mathrm{VE}, \mathrm{VT}$, breathing frequency (f), and $\dot{\mathrm{V}} \mathrm{O}_{2}$, which were measured by a pneumotachometer (DirectConnect ${ }^{\mathrm{TM}}$ Flow Sensor, MedGraphics Corporation, St. Paul, MN) used in conjunction with a metabolic cart (Ultima CPX, MedGraphics Corporation, St. Paul, MN). The metabolic cart recorded these measurements continuously throughout the SBT retrieving breath-to-breath data points and displayed them in a table for future calculation of $\mathrm{VEqO}_{2}$ and RSBI. No measurements were taken from the mechanical ventilator so that all parameters pertaining to the calculation of $\mathrm{VEqO}_{2}$ and $\mathrm{RSBI}$ were retrieved from the same source and time. The equations for $\mathrm{VEqO}_{2}$ and $\mathrm{RSBI}$ are as follows:

$$
\mathrm{VEqO}_{2}=\mathrm{VE}(\mathrm{L} / \mathrm{min}) / \dot{\mathrm{VO}} 2(\mathrm{~L} / \mathrm{min})[32]
$$

$\mathrm{RSBI}=\mathrm{f}$ (breaths $/$ minute $) / \mathrm{VT}(\mathrm{mL} / \mathrm{min})$

The pneumotachometer was placed between the "Y" of the ventilator circuit and the endo-tracheal tube. All other participant data were recorded from monitors and bedside assessment.

\section{Protocol}

Before the measurement of $\mathrm{VEqO}_{2}$ and RSBI was initiated, demographic data from the Electronic Medical Record were recorded on a flow sheet and included: age, weight, gender, reason for mechanical ventilation, the number of hours the participant received mechanical ventilation prior to the study, the number of failed SBTs prior to the study, the level of ventilator support before the study, and the level of ventilator support during the SBT. The following data were recorded on a flow sheet throughout the study: heart rate, $\mathrm{f}$, blood pressure (if available by continuous monitoring), oxygen saturation by pulse-oximeter, and fraction of inspired oxygen. Data pertaining to the determination of $\mathrm{VEqO}_{2}$ and the RSBI were recorded continuously by the metabolic cart and recorded on the flow sheet as well. The data were analyzed over five breaths $(i)$ while the participant was on their usual ventilator support before the study, (ii) immediately after the start of the SBT, (iii) at the midpoint of the SBT, and (iv) at the end of the 30-min SBT or at failure and subsequent stopping of the SBT, whichever came first. Immediately before the SBT, a sterile pneumotachometer was placed between the "Y" of the ventilator circuit and the ET-tube. As per the institutions weaning guidelines, an SBT was initiated for up to $30 \mathrm{~min}$ in duration using $100 \%$ automatic tube compensation or per managing physician's order. The pneumotachometer was removed from the circuit at the end of the SBT. The decision to return the participant to ventilator support or to discontinue ventilator support was decided per the institution's weaning guidelines or the managing physician.

\section{Endpoint definitions}

\section{Extubation and SBT success}

An extubation success was defined as a participant not receiving invasive or noninvasive ventilator support for $>72 \mathrm{~h}[34,35]$ after extubation. An SBT success was defined as passing the SBT according to the institution's weaning guidelines (Figure 1).

\section{Extubation and SBT failure}

An extubation failure was defined as a participant needing invasive or noninvasive ventilator support $\leq 72 \mathrm{~h}$ of extubation. A SBT failure was defined as a participant failing the SBT according to the institution's weaning guidelines (Figure 1).

\section{Statistical analysis}

The primary endpoint of this pilot project assessed a difference in mean $\mathrm{VEqO}_{2}$ between participant groups of SBT pass or failure and, secondarily, extubation success or failure. A Mann-Whitney $U$ test was used to examine differences in the median $\mathrm{VEqO}_{2}$ between the study groups using an alpha level of 0.05 and beta of 0.20 with the coinciding interquartile range reported. SPSS statistical software (v.22, SPSS Inc., Chicago, IL, USA) was used for statistical analysis.

\section{RESULTS}

A total of 34 participants were enrolled into the study. Of those, 31 were included in the SBT analysis and 3 were excluded (Figure 2). Of the 31 study participants, 20 (65\%) passed the study SBT and 11 (35\%) failed the SBT (five received tracheostomy after failing the study SBT). Six participants who failed the SBT were not immediately extubated after the study SBT completion; therefore, these participants were not included in the extubation outcome analysis. 


\section{FIGURE 1}

Spontaneous breathing trial and extubation criteria.

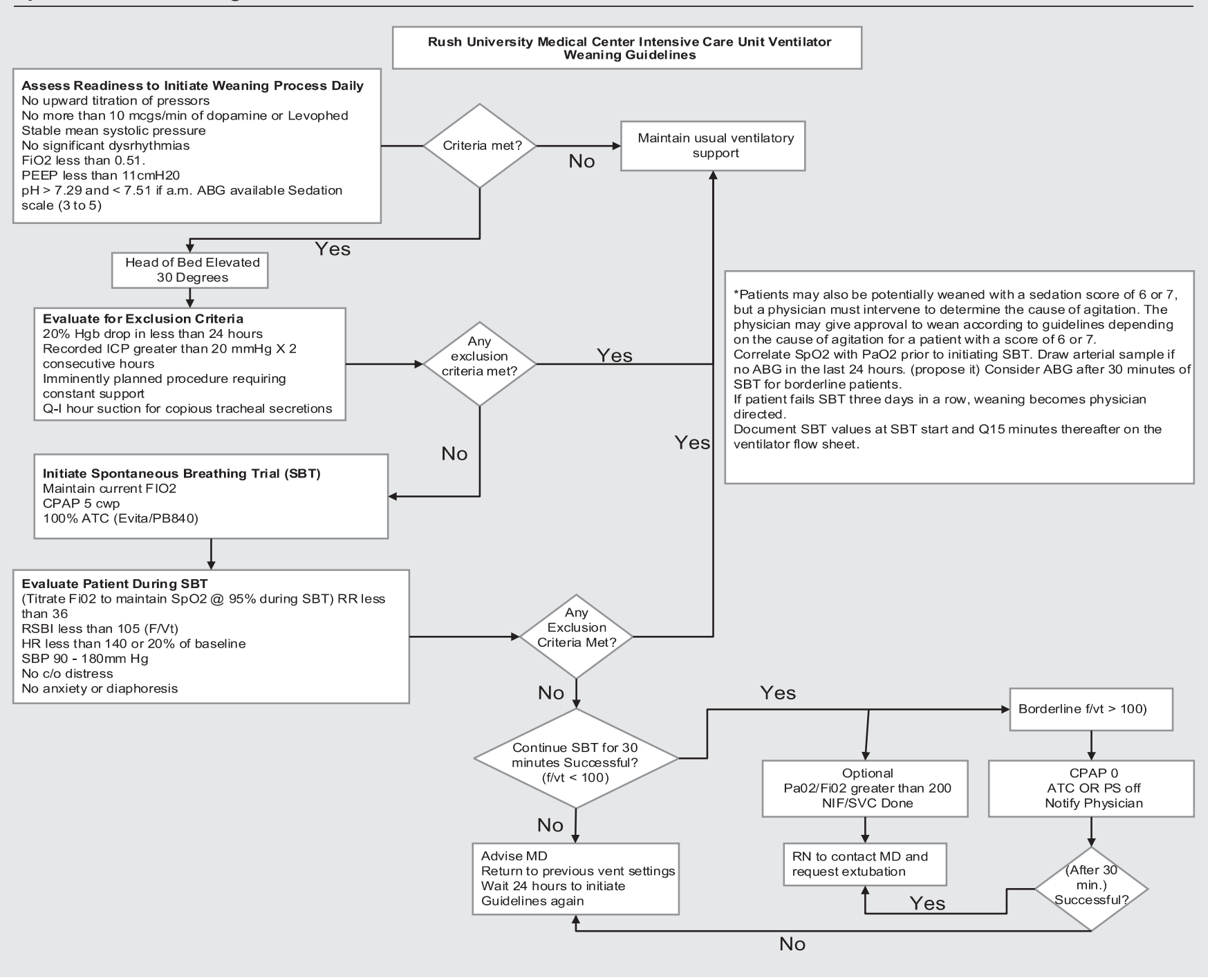

Out of 20 participants who passed the study SBT, 14 (70\%) were successfully extubated and six (30\%) failed the extubation. Of the six that failed extubation, one participant was reintubated for hypercapnic respiratory failure, one for hypoxic respiratory failure, two for a procedure, and two for inability to protect airways.

Table 1 depicts the baseline characteristics of the SBT and extubation group. The median age of the study participants was 58-66 years. Males and females represented almost equal number of participants in all groups except in the SBT fail group that had a higher proportion of females. Median duration of mechanical ventilation was $48 \mathrm{~h}$ in the SBT fail group and between 82 and $89 \mathrm{~h}$ in all other three groups. The primary reason for initiation of mechanical ventilation was airway protection followed by respiratory failure and other causes.

\section{SBT outcome}

Table 2 depicts the median $\mathrm{VEqO}_{2}, \dot{\mathrm{V}} \mathrm{O}_{2}, \mathrm{VE}$, and RSBI during the SBT in participants who passed and failed the SBT. These variables were measured continuously throughout the duration of the SBT. Because of the difference in the SBT duration among participants, four time points were selected for data presentation: before SBT, at start of SBT, at mid SBT, and at end of SBT. There was no significant difference in median
$\mathrm{VEqO}_{2}$ before the SBT and at the start of the SBT between SBT pass and failure groups. However, there was a significant difference in median $\mathrm{VEqO}_{2}$ among participants who passed the SBT compared with those who failed the SBT at the midpoint $(25.3[22-33]$ vs. $23.7[18-24] p=$ $0.035)$ and at the end $(25.5[23-34]$ vs. $21.3[20-24] p=0.017)$ of the study SBT (Figure 3). Our results showed no significant difference in median VE and median $\dot{V} \mathrm{O}_{2}$ during the SBT in participants who passed or failed the SBT.

RSBI was significantly lower in participants who passed the SBT at all four measurement points (before, $p=0.040$; start, $p=0.011$; mid, $p=0.001$; end, $p<0.001$ ) of the study SBT as compared with those who ended up failing the SBT. This is an auto-correlation because of the use of specific RSBI value as a criterion for determining the SBT outcome.

\section{Extubation outcome}

Table 3 shows median $\mathrm{VEqO}_{2}, \mathrm{VE}, \mathrm{VO}_{2}$ and RSBI during the SBT among participants who passed and failed extubation. As depicted in the table, those who were successfully extubated had an increase trend in median $\mathrm{VEqO}_{2}$ from the start (22.42 [17.9-30.8]) to the end (24.0.8 [21.1-34.6]) of the SBT trial. Similarly, the participants who failed extubation also 


\section{FIGURE 2}

Flow diagram presenting information regarding study enrollment. SBT, spontaneous breathing trial.

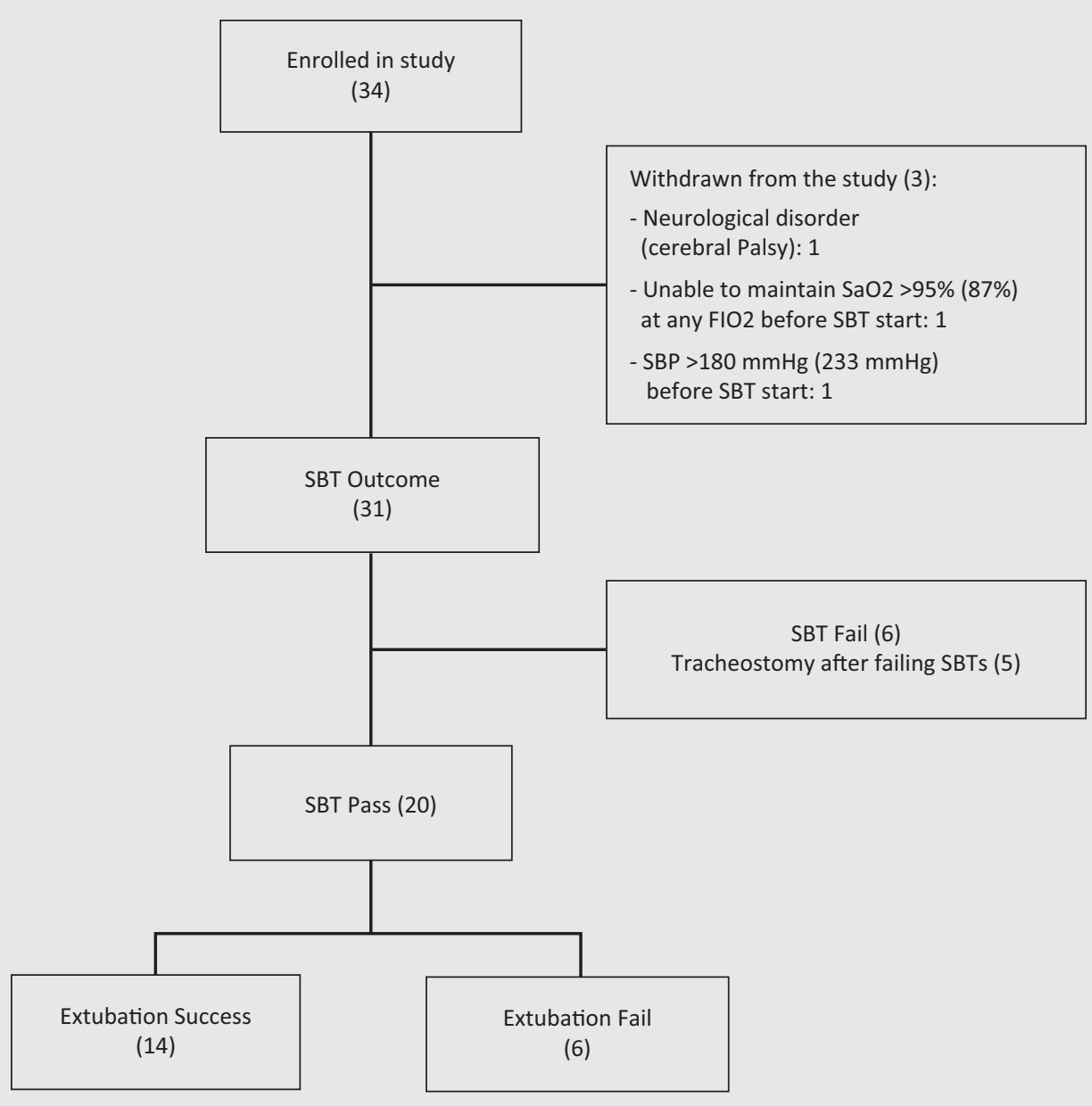

TABLE 1

\section{Participant characteristics}

\begin{tabular}{|c|c|c|c|c|}
\hline & \multicolumn{2}{|c|}{ SBT outcome $(n=31)$} & \multicolumn{2}{|c|}{ Extubation outcome $(n=20)$} \\
\hline & SBT pass (20) & SBT fail (11) & Extubation success (14) & Extubation failure (6) \\
\hline Age, median (IQR), year & $62.50(36-77.2)$ & $60(55-69)$ & $58(36-76)$ & $66.50(33-81)$ \\
\hline Male/female, no. (\%) & $11(55) / 9(45)$ & $3(27) / 8(73)$ & $8(57) / 6(43)$ & $3(50) / 3(50)$ \\
\hline Weight, median (IQR), kg & $79.15(69-109)$ & $80.90(69-86)$ & $88.25(67-112)$ & $76.50(65-114)$ \\
\hline Hours on ventilator before study SBT, median (IQR) & $82.50(37-120)$ & $48(42-96)$ & $82.50(33-112)$ & $89(42-189)$ \\
\hline \multicolumn{5}{|l|}{ Reason for intubation, no. (\%) } \\
\hline Airway protection & $10(50)$ & $5(46)$ & $6(43)$ & $4(66)$ \\
\hline Respiratory failure & $9(45)$ & $3(27)$ & $8(57)$ & $1(17)$ \\
\hline Others & $1(5)$ & $3(27)$ & 0 & $1(17)$ \\
\hline Time from study SBT to extubation, median (IQR), hours & $5(2.4-26.5)$ & $23.50(18-44.2)$ & $4.50(2-43)$ & $9.50(3.5-27)$ \\
\hline
\end{tabular}

Note: SBT, spontaneous breathing trial; IQR, interquartile range.

had an increase trend in median $\mathrm{VEqO}_{2}$ from the start (23.28 [19.729.8]) to the end (26.6 [24.4-30.4]) of the SBT trial (Figure 4). However, there was no significant difference in median $\mathrm{VEqO}_{2}$ among those participants who passed and failed extubation before $(p=0.312)$, at the start $(p=0.904)$, at the midpoint $(p=0.659)$, and at the end $(p=0.547)$ of the SBT trial.

There was no significant difference among extubation success and failure groups in median $\mathrm{VE}, \dot{\mathrm{VO}}{ }_{2}$, and RSBI.

\section{DISCUSSION}

In this study of adult intensive care unit (ICU) patients weaning from mechanical ventilation, $\mathrm{VEqO}_{2}$ and $\mathrm{RSBI}$ were not different between participants that failed extubation and those that successfully extubated. $\mathrm{VEqO}_{2}$ was significantly different at mid-and end-SBT between patients that passed and failed the SBT, and RSBI was significantly different at all four points measured during the SBT between participants that failed the SBT and those that passed the SBT. 
Since $\mathrm{VEqO}_{2}$ is the ratio of minute ventilation to oxygen consumption, a higher value would represent a greater efficiency of breathing: volumes moved at lower oxygen costs when the patient is at rest $[14,15$, 32]. Ruppel [14] defined $\mathrm{VEqO}_{2}$ as the ratio of $\mathrm{VE}$ in $\mathrm{L}$ to $\dot{\mathrm{VO}} \mathrm{O}_{2}$ in $\mathrm{mL} /$ min; however, we reported our values in $\mathrm{L} / \mathrm{L} \dot{V} \mathrm{O}_{2}$ similar to other authors [32]. We hypothesized that $\mathrm{VEqO}_{2}$ would be higher in patients that successfully extubated since we expected them to be able to breathe more efficiently prior to extubation compared with those that would fail extubation. However, $\mathrm{VEqO}_{2}$, a measure of the efficiency of breathing and a possible noninvasive surrogate for WOB, was not different between extubation groups in our study population. One study using artificial neural networks, showed that the value of WOB as a predictor for extubation outcome was highly sensitive (0.96) in a surgical ICU population of 97 adults [26]. The majority of the patients that extubated successfully exhibited a low WOB (<10 J); however, the population in their study was

TABLE 2

\section{SBT outcome}

\begin{tabular}{|c|c|c|c|}
\hline & SBT pass $(20)$ & SBT fail (11) & $p$ \\
\hline \multicolumn{4}{|l|}{ Before SBT } \\
\hline $\mathrm{VEqO}_{2}$ & $22.30(19-32.8)$ & $24.50(19-31.3)$ & 0.773 \\
\hline $\mathrm{VE}, \mathrm{L} / \mathrm{min}$ & $8.13(6-10.3)$ & $8.56(5.1-11.3)$ & 0.670 \\
\hline$\dot{\mathrm{VO}}_{2}, \mathrm{~L} / \mathrm{min}$ & $0.33(0.3-0.41)$ & $0.36(0.22-0.43)$ & 0.451 \\
\hline RSBI & $37.89(31-59.8)$ & $56.15(45-79.3)$ & 0.040 \\
\hline \multicolumn{4}{|c|}{ At start SBT } \\
\hline $\mathrm{VEqO}_{2}$ & $23.05(18-30)$ & $24.85(17-26)$ & 0.901 \\
\hline $\mathrm{VE}, \mathrm{L} / \mathrm{min}$ & $7.29(6-9.2)$ & $7.68(5.3-9.1)$ & 0.611 \\
\hline$\dot{\mathrm{V}} \mathrm{O}_{2}, \mathrm{~L} / \mathrm{min}$ & $0.33(0.27-0.37)$ & $0.33(0.3-0.42)$ & 0.823 \\
\hline RSBI & $48.61(31.1-65.7)$ & $84.94(47.4-98.1)$ & 0.011 \\
\hline \multicolumn{4}{|l|}{ At mid SBT } \\
\hline $\mathrm{VEqO}_{2}$ & $25.35(22-33)$ & $23.73(18-24)$ & 0.035 \\
\hline $\mathrm{VE}, \mathrm{L} / \mathrm{min}$ & $8.60(6.9-10.7)$ & $8.12(7.4-9.67)$ & 0.403 \\
\hline $\mathrm{VO}_{2}, \mathrm{~L} / \mathrm{min}$ & $0.33(0.27-0.38)$ & $0.40(0.26-0.52)$ & 0.244 \\
\hline RSBI & $58.73(33.3-66.3)$ & $100.74(70-129.2)$ & 0.001 \\
\hline \multicolumn{4}{|l|}{ At end SBT } \\
\hline $\mathrm{VEqO}_{2}$ & $25.53(23-34)$ & $21.34(20-24)$ & 0.017 \\
\hline $\mathrm{VE}, \mathrm{L} / \mathrm{min}$ & $9.28(7.5-12.6)$ & $8.68(7.3-9.6)$ & 0.261 \\
\hline$\dot{\mathrm{V}} \mathrm{O}_{2}, \mathrm{~L} / \mathrm{min}$ & $0.35(0.3-0.43)$ & $0.40(0.31-0.46)$ & 0.528 \\
\hline $\mathrm{RSBI}$ & $46.33(29.8-71.9)$ & $117.64(82.3-129.6)$ & 0.000 \\
\hline
\end{tabular}

Note: All data are given as the median (interquartile range). Bold values indicate significance based on $\mathrm{p}$ value of 0.05. SBT, spontaneous breathing trial; $\mathrm{VEq \textrm {O } _ { 2 }}$, ventilatory equivalent for oxygen; $\mathrm{V}_{\mathrm{E}}$, minute volume; $\mathrm{VO}_{2}$, oxygen consumption; $R S B I$, rapid shallow breathing index. from a surgical ICU. Interestingly, the $\mathrm{VEqO}_{2}$ was slightly higher (not statistically) in our extubation failure group compared with the success group at all four points measured during the SBT. The reason for this finding is unclear. A possible reason $\mathrm{VEqO}_{2}$ values were not that different between extubation groups may be that there actually was no significant difference in WOB between the groups. RSBI values were not different between groups either, but a rapid shallow breathing pattern is one sign of an inability of the respiratory muscles to meet the workload demand. If RSBI values were different (higher in extubation failure patients and lower in patients with successful extubation) we might have more reason to believe that $\mathrm{WOB}$ was different and that $\mathrm{VEqO}_{2}$ would be as well. However, as mentioned previously, studies verifying the efficacy of the RSBI to predict extubation had varied outcomes [9-11]. Another possible reason $\mathrm{VEqO}_{2}$ was not that different between groups could be because of the small sample size.

\section{TABLE 3}

\section{Extubation outcome}

\begin{tabular}{|c|c|c|c|}
\hline & $\begin{array}{l}\text { Extubation } \\
\text { success (14) }\end{array}$ & $\begin{array}{l}\text { Extubation } \\
\text { failure (6) }\end{array}$ & $p$ \\
\hline \multicolumn{4}{|c|}{ Before SBT } \\
\hline $\mathrm{VEqO}_{2}$ & $21.11(18.25-33.6)$ & 23.55 (21.4-27.5) & 0.312 \\
\hline VE, L/min & $8.04(6.6-10.5)$ & $8.24(6.4-10.35)$ & 1.000 \\
\hline$\dot{\mathrm{VO}}_{2}, \mathrm{~L} / \mathrm{min}$ & $0.35(0.29-0.44)$ & $0.32(0.29-0.41)$ & 0.718 \\
\hline RSBI & $40.63(28.9-62.9)$ & 35.06 (28.7-61.7) & 0.779 \\
\hline \multicolumn{4}{|c|}{ At start SBT } \\
\hline $\mathrm{VEqO}_{2}$ & $22.42(17.9-30.8)$ & 23.28 (19.7-29.8) & 0.904 \\
\hline VE, L/min & $6.88(5.9-11.2)$ & 8.09 (6.54-9.08) & 0.779 \\
\hline$\dot{\mathrm{VO}}_{2}, \mathrm{~L} / \mathrm{min}$ & $0.30(0.27-0.4)$ & $0.33(0.31-0.35)$ & 0.779 \\
\hline RSBI & $44.86(24.6-70.5)$ & $50.31(42.6-60.4)$ & 0.547 \\
\hline \multicolumn{4}{|c|}{ At mid SBT } \\
\hline $\mathrm{VEqO}_{2}$ & $24.29(21.8-34.9)$ & $27.14(24.2-30)$ & 0.659 \\
\hline VE, L/min & $8.86(6.7-11.1)$ & $8.21(7.1-10.5)$ & 0.718 \\
\hline$\dot{\mathrm{V}} \mathrm{O}_{2}, \mathrm{~L} / \mathrm{min}$ & $0.33(0.26-0.39)$ & $0.33(0.26-0.38)$ & 0.841 \\
\hline $\mathrm{RSBI}$ & $57.04(30.3-64.3)$ & $61.28(32.3-71.5)$ & 0.602 \\
\hline \multicolumn{4}{|l|}{ At end SBT } \\
\hline $\mathrm{VEqO}_{2}$ & $24.08(21.1-34.6)$ & $26.60(24.4-30.4)$ & 0.547 \\
\hline VE, L/min & $9.28(7.43-12.9)$ & $10.13(7.7-12.7)$ & 0.779 \\
\hline$\dot{\mathrm{VO}}_{2}, \mathrm{~L} / \mathrm{min}$ & $0.36(0.29-0.40)$ & $0.35(0.29-0.48)$ & 0.968 \\
\hline $\mathrm{RSBI}$ & $46.33(23.8-71.5)$ & $51.42(33.1-74.2)$ & 0.779 \\
\hline
\end{tabular}

Note: All data are given as the median (interquartile range). SBT, spontaneous breathing trial; $V E q \mathrm{O}_{2}$, ventilatory equivalent for oxygen; $V_{E}$, minute volume; $\dot{V} \mathrm{O}_{2}$, oxygen consumption; RSBI, rapid shallow breathing index.

\section{FIGURE 3}

Median $\mathrm{VEqO}_{2}$ during spontaneous breathing trial (SBT) and SBT outcome.

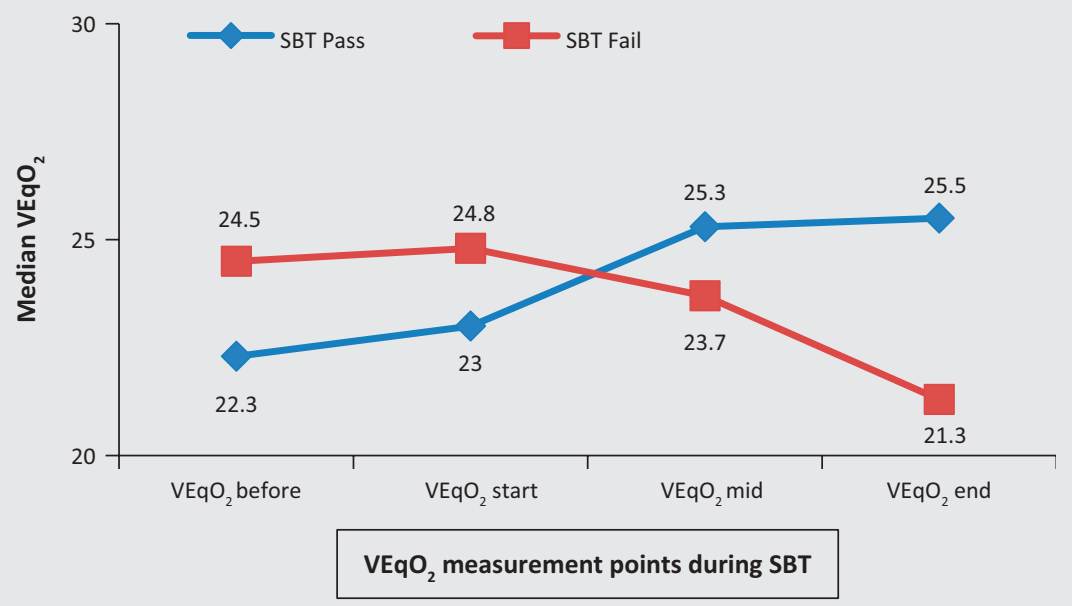




\section{FIGURE 4}

Median $\mathrm{VEqO}_{2}$ during spontaneous breathing trial (SBT) and extubation outcome.

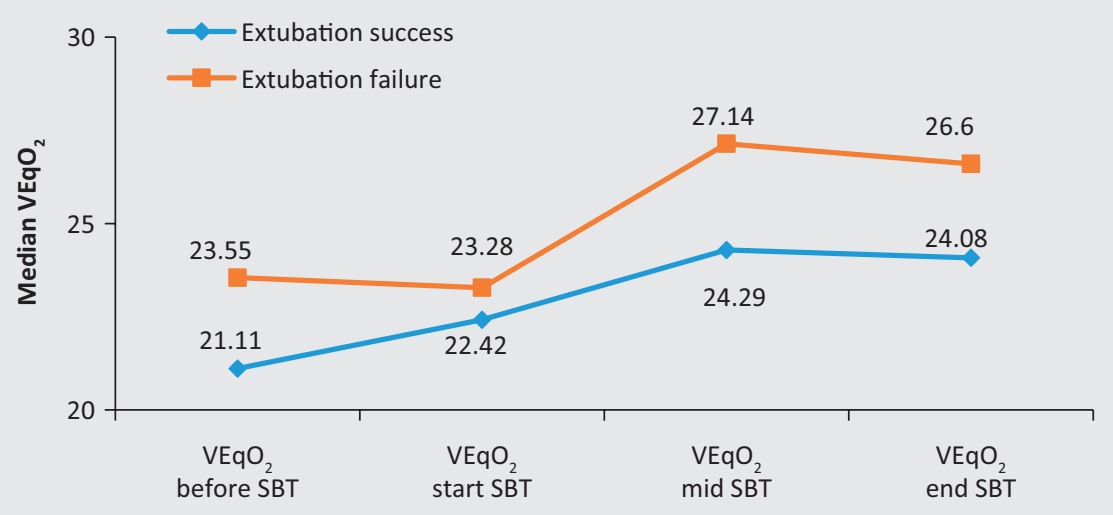

$\mathrm{VEqO}_{2}$ measurement points during SBT

$\mathrm{VEqO}_{2}$ may show differences in SBT outcomes, but not differences between extubation outcomes due to factors that change in the respiratory system after the airway has been removed. More recent literature has posited that predictors for extubation outcomes should be separated from SBT outcomes since they assess different objects [36]. Conclusions drawn from predictors for extubation outcomes are complicated by factors important to the airway itself and variables that change after removing the endotracheal tube, such as secretions or swelling [1].

In 1990, Shikora et al. [16] estimated WOB as the $\Delta \dot{V} \mathrm{O}_{2}$ during mechanical ventilation and compared that to spontaneous breathing. They found that a WOB (expressed as $\Delta \dot{V} \mathrm{O}_{2}$ as a percentage of $\dot{V} \mathrm{O}_{2}$ ) of $15 \%$ was a reference value below which predicted successful extubation and above which predicted failure to extubate with a sensitivity of $100 \%$ and a specificity of $80 \%$. This study was performed with 20 longer-term ventilated patients, 19 of which required greater than 2 weeks of mechanical ventilation. Again, in 1994, Shikora et al. showed that the OCOB reliably predicted success in all five patients that successfully extubated and predicted failure in 20 of 23 that were extubated with a sensitivity of $100 \%$ and a specificity of $87 \%$ [17]. The OCOB had a much higher reliability than the RSBI in their study; the participants in this study were long-term mechanically ventilated patients. In the current study, the participants in the extubation analysis were only ventilated a median of just over $80 \mathrm{~h}$ or about 3 days. It is possible that $\mathrm{VEqO}_{2}$ cannot predict outcomes between groups of these shorter-term mechanically ventilated participants. The use of $\mathrm{VEqO}_{2}$ in longer-term mechanically ventilated patients still needs to be investigated.

In contrast with extubation outcomes, $\mathrm{VEqO}_{2}$ between SBT outcome groups measured at the midpoint and at the endpoint of the 30-min SBT were different. Breathing was more efficient at these points among those who passed the SBT according to the criteria shown in Figure 1 . This difference could be a useful indicator of a patient's ability to sustain spontaneous breathing when weaning patients from the ventilator in the clinical setting. In more recent studies, the OCOB, or $\Delta \dot{V} \mathrm{O}_{2}$ from ventilator support to SBT or reduced levels of support, was not assessed for extubation outcomes, but was different between patients who passed or failed the SBT [18, 19, 20, 37]. However, study results varied. Yang [12] found that patients that failed SBTs had higher baseline $\dot{\mathrm{V}} \mathrm{O}_{2}$ and were less able to increase that value when support was decreased, whereas Teixeira [19] and Mitsuoaka [20] showed that decreases in central venous oxygen saturation or higher increases in $\dot{V} \mathrm{O}_{2}$ at rest generally predicted fatigue. Our patients did not show significant difference in $\dot{\mathrm{V}} \mathrm{O}_{2}$ values over time between SBT success and failure groups.

A limitation of this study is the small sample size. Study SBTs were not assessed serially until the time of extubation where measurements could be taken from the SBT directly preceding extubation attempts for every study participant. This resulted in a small sample size, particularly for the extubation outcome groups as we used only those SBTs measured immediately prior to extubation from those that passed their SBTs to make the correct comparison between extubation outcome groups. Although the sample size is small even in the SBT outcome groups, we found a significant difference in $\mathrm{VEqO}_{2}$ between the SBT success and failure groups. This finding is similar to RSBI, and there is no trend indicating that increasing the sample would lead to a significant finding in extubation outcomes. It is also important to note that the institution's weaning guidelines include a RSBI threshold of 105 as a parameter for passing or failing an SBT. Therefore, the RSBI was auto-correlated and expected to be different between SBT groups in this study since that was one of the parameters initially used to classify the groups.

Further study of $\mathrm{VEqO}_{2}$ in long-term mechanically ventilated patients may prove beneficial since many of the previous studies showed $\dot{\mathrm{V}} \mathrm{O}_{2}$ or $\mathrm{WOB}$ as a predictor of extubation outcomes [16, 17, 27]. Perhaps $\mathrm{VEqO}_{2}$ as an indicator of WOB may be used to recondition the diaphragm in these patients. It is worth noting that some predictors applied universally across patient populations may actually slow liberation from the ventilator and should not be the only variables used when a patient is extubated [38-40].

In conclusion, $\mathrm{VEqO}_{2}$ distinguishes between SBT success and failure but does not distinguish between extubation success or failure in mechanically ventilated patients in our population. Further study of $\mathrm{VEqO}_{2}$ is warranted.

\section{Contributors}

All authors contributed to the conception or design of the work, the acquisition, analysis, or interpretation of the data. All authors were involved in drafting and commenting on the paper and have approved the final version.

\section{Funding}

This study did not receive any specific grant from funding agencies in the public, commercial, or not-for-profit sectors.

\section{Competing interests}

All authors have completed the ICMJE uniform disclosure form at www. icmje.org/coi_disclosure.pdf and declare: Troy Ellens, Ramandeep Kaur, and Kelly Roehl have no conflicts of interest. Meagan Dubosky: Halyard (Consultant); David Vines: Bayer Healthcare (Member, Medical Advisory Board), Salter Labs (Member, Medical Advisory Board), and Teleflex (Lecturer, Consulting) 


\section{REFERENCES}

1. MacIntyre NR, Evidence-based guidelines for weaning and discontinuing ventilatory Support: A collective task force facilitated by the American College of Chest Physicians; the American Association for Respiratory Care; and the American College of Critical Care Medicine. Chest 2001;120: 6_suppl):375S-96S. doi: 10.1378/chest.120.6_suppl.375S.

2. Ely EW, Baker AM, Dunagan DP, et al., Effect on the duration of mechanical ventilation of identifying patients capable of breathing spontaneously. NEnglJMed 1996;335(25): 1864-9. doi: 10.1056/NEJM199612193352502.

3. Epstein SK, Ciubotaru RL, Wong JB, Effect of failed extubation on the outcome of mechanical ventilation. Chest 1997;112(1): 186-92. doi: 10.1378/chest.112.1.186

4. Frutos-Vivar F, Esteban A, Apezteguia C, et al., Outcome of reintubated patients after scheduled extubation. J Crit Care 2011;26(5): 502-9. doi: 10.1016/j.jcrc.2010.12.015.

5. Schmidt GA, Girard TD, Kress JP, et al., Official executive summary of an American Thoracic Society/American College of Chest Physicians Clinical Practice Guideline: Liberation from mechanical ventilation in critically ill adults. Am J Respir Crit Care Med 2017;195(1): 115-19. doi: 10.1164/rccm.201610-2076ST.

6. Meade M, Guyatt G, Cook D, et al., Predicting success in weaning from mechanical ventilation*. Chest 2001;120: 6 suppl):400S-24S. doi: 10.1378/chest.120.6_suppl.400S.

7. Frutos-Vivar F, Ferguson ND, Esteban A, et al., Risk factors for extubation failure in patients following a successful spontaneous breathing trial. Chest 2006;130(6): 1664-71. doi: 10.1378/chest.130.6.1664.

8. MacIntyre NR, The ventilator discontinuation process: An expanding evidence base. Respir Care 2013;58(6): 1074-86. doi: 10.4187/respcare.02284.

9. Lee KH, Hui KP, Chan T, Tan WC, Lim TK, Rapid shallow breathing (frequency-tidal volume ratio) did not predict extubation outcome. Chest 1994;105(2): 540-3. doi: 10.1378/chest.105.2.540.

10. Krieger BP, Campos M, Weaning parameters. Chest 2002;122(6): 18734. doi: $10.1378 /$ chest.122.6.1873.

11. Krieger BP, Isber J, Breitenbucher A, Throop G, Ershowsky P, Serial measurements of the rapid-shallow-breathing index as a predictor of weaning outcome in elderly medical patients. Chest 1997;112(4): 1029-34. doi: 10.1378/chest.112.4.1029.

12. Yang KL, Tobin MJ, A prospective study of indexes predicting the outcome of trials of weaning from mechanical ventilation. N Engl J Med 1991;324(21): 1445-50. doi: 10.1056/NEJM199105233242101.

13. Nemer SN, Barbas C, Caldeira JB, et al., A new integrative weaning index of discontinuation from mechanical ventilation. Crit Care 2009;13(5): R152. doi: 10.1186/cc8051

14. Ruppel GL. Manual of pulmonary function testing. 9th ed. St. Loius, MO: Mosby Elsevier; 2009.

15. Staudinger T, Kordova H, Roggla M, et al., Comparison of oxygen cost of breathing with pressure-support ventilation and biphasic intermittent positive airway pressure ventilation. Crit Care Med 1998;26(9): 1518. doi: 10.1097/00003246-199809000-00018

16. Shikora SA, Bistrian BR, Borlase BC, Blackburn GL, Stone MD, Benotti PN, Work of breathing: Reliable predictor of weaning and extubation. Crit Care Med 1990;18(2): 157-62. doi: 10.1097/00003246-199002000-00006.

17. Shikora SA, Benotti PN, Johannigman JA, The oxygen cost of breathing may predict weaning from mechanical ventilation better than the respiratory rate to tidal volume ratio. Arch Surg 1994;129(3): 269-74. doi: 10.1001/archsurg.1994.01420270045011.

18. Bellani G, Foti G, Spagnolli E, et al., Increase of oxygen consumption during a progressive decrease of ventilatory support is lower in patients failing the trial in comparison with those who succeed. Anesthesiology 2010;113(2): 378-85. doi: 10.1097/ALN.0b013e3181e81050.

19. Teixeira $\mathrm{C}$, Central venous saturation is a predictor of reintubation in difficult-to-wean patients. Crit Care Med 2010;38(2): 491. doi: 10.1097/ CCM.0b013e3181bc81ec

20. Mitsuoka M, Utility of measurements of oxygen cost of breathing in predicting success or failure in trials of reduced mechanical ventilatory support. Respir Care 2001;46(9): 902

21. Kondili E, Prinianakis G, Alexopoulou C, Vakouti E, Klimathianaki M, Georgopoulos D, Respiratory load compensation during mechanical ventilation - Proportional assist ventilation with load-adjustable gain factors versus pressure support. Intensive Care Med 2006;32(5): 692-9. doi: 10.1007/s00134-006-0110-0.
22. Jubran A, Tobin MJ, Pathophysiologic basis of acute respiratory distress in patients who fail a trial of weaning from mechanical ventilation. Am J Respir Crit Care Med 1997;155(3): 906-15. doi: 10.1164/ ajrccm.155.3.9117025.

23. Bosma K, Ferreyra G, Ambrogio C, et al., Patient-ventilator interaction and sleep in mechanically ventilated patients: Pressure support versus proportional assist ventilation. Crit Care Med 2007;35(4): 1048-54. doi: 10.1097/01.CCM.0000260055.64235.7C.

24. Delaere S, Roeseler J, D'hoore W, et al., Respiratory muscle workload in intubated, spontaneously breathing patients without COPD: Pressure support vs proportional assist ventilation. Intensive Care Med 2003;29(6): 949-54. doi: 10.1007/s00134-003-1704-4.

25. Passam F, Hoing S, Prinianakis G, Siafakas N, Milic-Emili J, Georgopoulos D, Effect of different levels of pressure support and proportional assist ventilation on breathing pattern, work of breathing and gas exchange in mechanically ventilated hypercapnic COPD patients with acute respiratory failure. Respiration 2003;70(4): 355. doi: 10.1159/000072897

26. Banner MJ, Euliano NR, Martin AD, Al-Rawas N, Layon AJ, Gabrielli A, Noninvasive work of breathing improves prediction of post-extubation outcome. Intensive Care Med 2012;38(2): 248-55. doi: 10.1007/ s00134-011-2402-2.

27. Fiastro J, Habib M, Shon B, Campbell S, Comparison of standard weaning parameters and the mechanical work of breathing in mechanically ventilated patients. Chest 1988;94(2): 232-8. doi: 10.1378/chest.94.2.232.

28. Gluck EH, Barkoviak MJ, Balk RA, Casey LC, Silver MR, Bone RC, Medical effectiveness of esophageal balloon pressure manometry in weaning patients from mechanical ventilation. Crit Care Med 1995;23(3): 504-9. doi: 10.1097/00003246-199503000-00015.

29. Levy MM, Miyasaki A, Langston D, Work of breathing as a weaning parameter in mechanically ventilated patients. Chest 1995;108(4): 101820. doi: 10.1378/chest.108.4.1018.

30. Varelmann D, Wrigge H, Zinserling J, Muders T, Hering R, Putensen C, Proportional assist versus pressure support ventilation in patients with acute respiratory failure: Cardiorespiratory responses to artificially increased ventilatory demand. Crit Care Med 2005;33(9): 1968-75. doi: 10.1097/01.CCM.0000178191.52685.9B.

31. Wrigge H, Golisch W, Zinserling J, Sydow M, Almeling G, Burchardi H, Proportional assist versus pressure support ventilation: Effects on breathing pattern and respiratory work of patients with chronic obstructive pulmonary disease. Intensive Care Med 1999;25(8): 790-8. doi: 10.1007/ s001340050954.

32. Shelledy DC, Rau JL, Thomas-Goodfellow L, A comparison of the effects of assist-control, SIMV, and SIMV with pressure support on ventilation, oxygen consumption, and ventilatory equivalent. Heart Lung 1995;24(1): 67-75. doi: 10.1016/S0147-9563(05)80097-4.

33. Cherniack RM, The oxygen consumption and efficiency of the respiratory muscles in health and emphysema. J Clin Invest 1959;38(3): 494. doi: 10.1172/JCI103826

34. Thille AW, Harrois A, Schortgen F, Brun-Buisson C, Brochard L, Outcomes of extubation failure in medical intensive care unit patients. Crit Care Med 2011;39(12): 2612-18. doi: 10.1097/CCM.0b013e3182282a5a.

35. Seymour CW, Martinez A, Christie JD, Fuchs BD, The outcome of extubation failure in a community hospital intensive care unit: A cohort study. Crit Care 2004;8(5): R322. doi: 10.1186/cc2913

36. Gobert F, Yonis H, Tapponnier R, et al., Predicting extubation outcome by cough peak flow measured using a built-in ventilator flow meter. Respir Care 2017;62(12): 1505-19. doi: 10.4187/respcare.05460.

37. Miwa K, Mitsuoka M, Takamori S, Hayashi A, Shirouzu K, Continuous monitoring of oxygen consumption in patients undergoing weaning from mechanical ventilation. Respiration 2003;70(6): 623-30. doi: $10.1159 / 000075209$

38. Ko R, Ramos L, Chalela JA, Conventional weaning parameters do not predict extubation failure in neurocritical care patients. Neurocrit Care 2009;10(3): 269-73. doi: 10.1007/s12028-008-9181-9.

39. Tanios MA, Nevins ML, Hendra KP, et al., A randomized, controlled trial of the role of weaning predictors in clinical decision making. Crit Care Med 2006;34(10):2530-35. doi: 10.1097/01.CCM.0000236546.98861.25.

40. Savi A, Teixeira C, Silva JM, et al., Weaning predictors do not predict extubation failure in simple-to-wean patients. J Crit Care 2012;27(2): 221. e1-8. doi: 10.1016/j.jcrc.2011.07.079. 